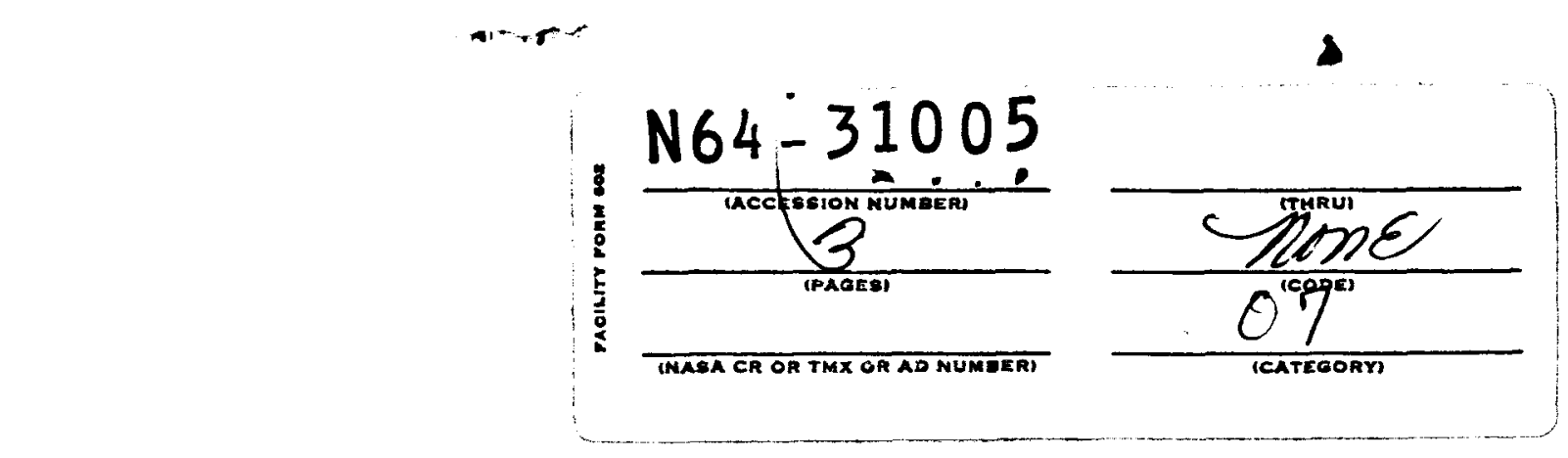

[Reprinted from the Journal of the American Chemical Society, 86, 3.572 (1964)]

Copyright 1964 by the American Chemical Society and reprinted by permission of the copyright owner.

\section{Visible Absorption Spectra of Lithium, Sodium, and Potassium in Molten Lithium Chloride Potassium Chloride}

Sir:

In order to elucidate the nature of the species formed upon the addition of an alkali metal to an alkali halide melt, the absorption spectra obtained upon the addition of $\mathrm{Li}, \mathrm{Na}$, and $\mathrm{K}$ to molten $\mathrm{LiCl} \mathrm{KCl}$ were measured. The eutectic mixture of $\mathrm{LiCl}$ and $\mathrm{KCl}$ was used in order that the measurements be made at as low a temperature as possible. Although the attack of heated alkali metal vapors has restricted the use of silicate containers in such work, it was not found to be a primary problem. The absorption spectra obtained can all be characterized by a band with a peak maximum at $530 \mathrm{~m} n \mu$.

Quartz cuvettes, $1 \mathrm{~cm}$. in diameter, were used as containers. Although heated alkali metal vapors react with silicates, it was found that if the salts were anhydrous, the alkali metal would dissolve in the salt without discoloring that portion of the cell containing the melt. However, there were irreversible losses of alkali metal vapor for the following reasons: reaction of the metal with water on the container walls, ${ }^{1}$ reaction of the metal with the glass cuvette itself, and distillation of the metal from the solvent to other parts of the evacuated container. The presence of adsorbed water on the glass container has been shown to be a source of decomposition in the preparation of alkali-metal-ammonia solutions. ${ }^{2}$

The cells were wrapped with Inconel heating strips and placed in an insulating container. The steadystate temperatures were controlled by means of a Variac to within $\pm 5^{\circ}$. The temperature of the system was measured by means of a platinum-rhodium $(13 \%)$ thermocouple. All measurements were made at $100^{\circ}$.

The spectra were obtained by use of a Beckman DK, double-beam recording spectrophotometer. Each

(1) I. Warshawsky, J. Inorg. Nucl. Chem., 25, 919 (1963).

(2) "Solutions Metal-Ammoniac; Proprietes Physicochimiques," G. l.epoutre and M. J. Sienko, Ed., Catholic University Press, Lille, France, 1963 (distributed by W. A. Benjamin Inc, New York, N. Y.). metal-salt mixture was compared to air in the reference compartment. The base line for the system was obtained by running the spectru mof the salt mixture alone when all the metal had left the system. In this way the problems in reproducing the exact temperature, concentration, and configuration of the sample cell were eliminated. The results obtained essentially enabled us to calculate a spectrum of the metal-salt system as compared with the identical salt system.

The standard preparation of molten salt halides was found to have inherent difficulties. In the salt melted in iacuo, washed with the appropriate halide gas, then with a dry inert gas, and filtered through Pyrex glass wool, it was found that not all hydrolysis products were removed and that often residual amounts of halogren gas reacted with the alkali metals added. In order to overcome the difficulties produced by heating the salt in the presence of water and by introducing halogen gases into the system, a new purification technique was used. ${ }^{3}$ It was found that anhydrous salts. could be obtained by washing with liquid ammonia. This procedure eliminated the possibility of hydrolysis since the salt was not heated until all the water was removed. This procedure also eliminated the use of halide and halogen gases.

Preparation of Metal-Molten Salt Solutions.Reagent grade $\mathrm{LiCl}$ and $\mathrm{KCl}$ were weighed out after vacuum drying to form the eutectic mixture (59 mole $\% \mathrm{LiCl}$ ). Removal of water from the salts was then done by washing with dry liquid ammonia. A system shown in Fig. 1 was used first to purify the salt mixture and then to prepare the metal salt solution. After repeatedly washing the salt mixture in region $B$ and pumping on the washed salt to remove residual ammonia, the potassium, and also the sodium, was distilled from region $A$ into region $C$. The system was the sealed off at $D$ while pumping. The salt mixture it region $B$ was easily transferred into region $C$ by tippins the ampoule and transferring the finely divided solic without heating. A heater was then placed about the

(3) I. Warshawsky and J. Greenberg, to be published. 


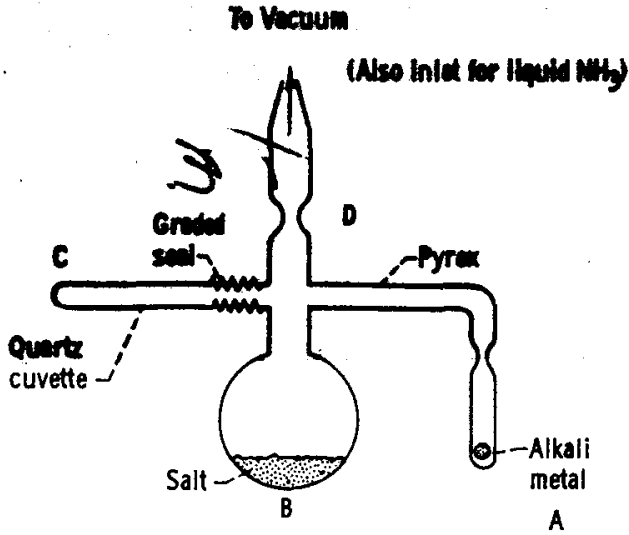

Irig. 1.-Apparatus for preparation of metal-salt systen.

cell and the solution formed by melting the eutectic mixture.

Since lithium badly discolored the cuvette upon heating, it was necessary to alter the previous procedure. The new procedure involved placing lithium in a side arm and dissolving it in liquid ammonia. A Dry Ice-acetone bath was then placed around region $\mathrm{B}$, which contained the salt; during the distillation of the anmonia to region $B$, some lithium was carried over in the diffusion stream. This process resulted in lithium metal being introduced into the water-free salt. The residual ammonia was removed from the salt by pumping. The system was sealed off, and the metal-salt mixture was transferred into region $C$. The metal-salt solution was formed by heating the salt without any discoloration of the glass at the glass-liquid interface.

The amount of sodium or potassium introduced into the salt was estimated by reacting similar amounts of metal as used with the salt mixtures with water vapor and measuring the pressure of hydrogen evolved. Initial quantities of metal were thus estimated to be $<10^{-5}$ mole

\section{Results}

The absorption spectra obtained with the addition of $\mathrm{Li}, \mathrm{Na}$, or $\mathrm{K}$ to the $\mathrm{LiCl}-\mathrm{KCl}$ entectic mixture can be characterized by a single visible band with a peak maximum at about $530 \mathrm{~m} \mu$. No additional bands or structures were observed in the range 3000 to $15,000 \AA$. The concentration of the alkali metal in the salt could not be kept at a constant value. The loss of alkali metals is probably due to reaction with water on the cuvette walls since the discoloration of the cuvette due to the alkali metal attack was minimal. Once the solution had been formed (i.e., the salt melted with the metal in it), the spectral readings during the first 1.5 min. indicated at least a $60 \%$ decrease in the concentration of alkali metal. Since the initial alkali metal addition was estimated to be $10^{-5}$ mole, the concentration after $15 \mathrm{~min}$. was considered to be of the order of $10^{-6}$ mole of metal. The liquid volume of the salt was approxinnately $10 \mathrm{cc}$. with the result that the concentration of metal in the salt was estimated to be $10^{-7} \mathrm{~mole} / \mathrm{cc}$. The data observed for the absorption band of $\mathrm{Li}, \mathrm{Na}$, and $\mathrm{K}$ in $\mathrm{LiCl}-\mathrm{KCl}$ are given in Fig. 2. The test conditions were as follows:

Temp., ${ }^{\circ} \mathrm{C}$.

Position of band peak, $m \mu$

Half-width, $\Delta \lambda_{1 / 2}, \mathrm{~m} \mu$

Metal concn., mole/cc.
$400 \pm 5$

530 (2.34 e.v.) $465-585(0.54$ e.v. $)$ $10^{-7}$

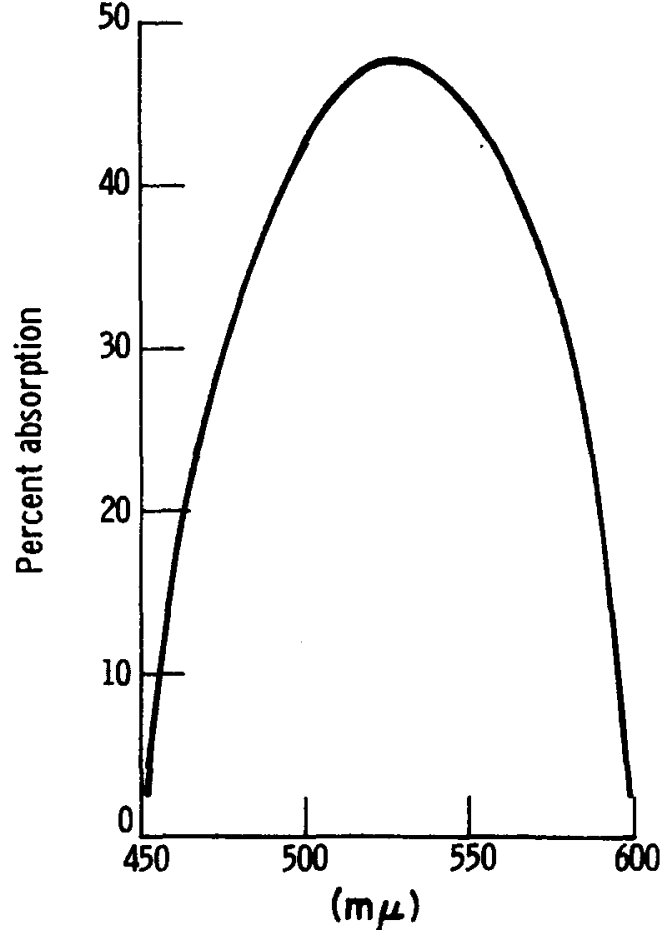

Irig. 2.- Absorption spectra of $\sim 10^{7}$ mole/cc. of $\mathrm{Li}, \mathrm{Na}$, and $\mathrm{K}$ in $\mathrm{LiCl}-\mathrm{KCl}$.

\section{Discussion}

The presence of a distinct visible band rather than a continuum indicates that the energy level structure typical of the metallic state is not present. The fact that $\mathrm{Li}, \mathrm{Na}$, and $\mathrm{K}$ all produced the same absorption pattern indicates that the absorbing species was the same in each case. It can, therefore, be suggested that either lithium or potassium atoms and molecules were responsible for the absorption. Since $\mathrm{LiCl}$ is less thermodynamically stable than either $\mathrm{NaCl}$ or $\mathrm{KCl}$, it is possible that the addition of $\mathrm{Na}$ or $\mathrm{K}$ to a system containing $\mathrm{LiCl}$ will displace lithium metal. If this were the case, it is somewhat surprising that the $s-p$ transition for lithium vapor was not observed. This argument has been used to indicate that the visible absorption of $\mathrm{Li}$ in $\mathrm{LiCl}$ is not due to the presence of lithium atoms with expanded outer electronic orbitals. ${ }^{4}$ Since potassium metal is the most volatile, it can also be suggested that by some kinetic exchange reaction potassium is released. Again, in this instance, it would be expected that the $s-p$ transition for potassium vapors would be observed. In addition, if such an exchange did take place, it might also be expected that some differences in the shape of the spectral band would be observed upon the addition of sodium to the melt. This might be expected since sodium is more volatile than lithium but less volatile than potassium.

Another explanation is that the electronic transitions observed are not of an electron associated with a particular cation core as in the case of a metal atom but that the electron is "delocalized." In this instance, the electron transitions would involve several cations similar to the formation of $\mathrm{F}$ centers in the solid. It would be of interest therefore to compare the oscillator strength of an electron trapped in the solid with the oscillator strength of a proposed electron in the melt. Since we have only an order of magnitude estimate of 
the metal concentration, and since the equation ${ }^{5}$ used involves the refractive index of the solid salt and complex polarizability of the electron in a solid, we can only estimate that the oscillator strength is less for the molten system than for the solid. This can be interpreted as indicating an interaction of the electron with the ions surrounding it.

(5) F. Seitz, "Modern Theory of Solids," McGraw-Hill Book Co., Inc., New York, N. X., 1940, p. 66.5.

Lewis Research Center

National Agronautics and

J. Graenberg

SPACE AdMTNISTRATION

Cleveland, Ohro

I. WARSHAWSKY

REChIVED MARCH 5, 1964 